\title{
Growth charts for Wolf-Hirschhorn syndrome (0-4 years of age)
}

\author{
T. Antonius • J. Draaisma $\cdot$ E. Levtchenko $\cdot$ N. Knoers • \\ W. Renier $\cdot$ C. van Ravenswaaij
}

Received: 23 May 2007 / Accepted: 14 August 2007 / Published online: 15 September 2007

(C) Springer-Verlag 2007

\begin{abstract}
Wolf-Hirschhorn syndrome is characterized by severe growth and mental retardation, microcephaly, seizures and 'Greek helmet' facies, caused by partial deletion of the short arm of chromosome 4. Growth charts are given from 0-4 years of age, based on the study of 101 individuals. Use of these specific growth charts is recommended, because standard growth charts are inapplicable for patients with WHS.
\end{abstract}

Keywords Wolf-Hirschhorn · WHS · Growth ·

Growth charts

\section{Abbreviations \\ WHS Wolf-Hirschhorn syndrome}

T. Antonius $(\triangle) \cdot J$. Draaisma $\cdot$ E. Levtchenko Department of Paediatrics,

Radboud University Medical Center Nijmegen,

Geert Grooteplein 10,

P.O. Box 9101, 6500 HB Nijmegen, The Netherlands

e-mail: t.antonius@cukz.umcn.nl

N. Knoers

Department of Human Genetics,

Radboud University Medical Center Nijmegen,

Nijmegen, The Netherlands

W. Renier

Department of Child Neurology,

Radboud University Medical Center Nijmegen,

Nijmegen, The Netherlands

C. van Ravenswaaij

Department of Genetics,

University Medical Center Groningen,

Groningen, The Netherlands

\section{Introduction}

Wolf-Hirschhorn syndrome (WHS) is caused by partial deletion of the short arm of chromosome 4 (4p-syndrome) $[3-5,7]$. Cardinal features of this rare syndrome are severe growth and mental retardation, microcephaly, seizures, "Greek helmet" facies and closure defects (Fig. 1) [1, 2, 4, 5, 7]. Growth in children with Wolf-Hirschhorn syndrome differs from that of normal children [1]. Up to date, there are no Wolf-Hirschhorn specific growth charts available.

\section{Materials and methods}

The study is based on data from 1,057 examinations of 101 children with WHS, 35 males and 66 females, born between 1975 and 2002. Data from 32 children were collected from records of individuals with WHS in the Netherlands. Another set of data was obtained from 69 children with WHS from Great Britain, North America, Germany and Australia who were contacted through WHS support groups. There were no exclusion criteria except growth hormone treatment. Thus, all children regardless of complicating disease such as heart defects, renal disease or feeding problems, were included. The number of observations in the Dutch group of children was higher than in the group of children from other countries. No difference in parameters related to growth was observed between Dutch and non-Dutch patients. The data used for creation of the growth charts were age at examination, height $(\mathrm{cm})$, weight $(\mathrm{kg})$ and head 


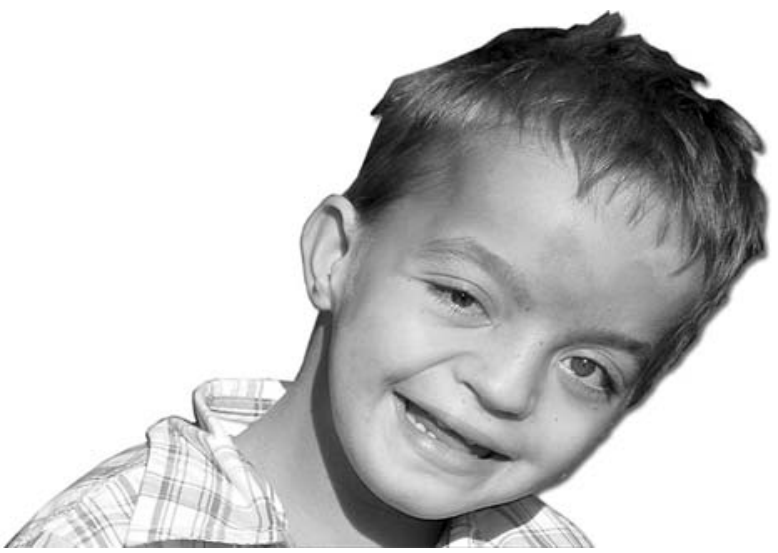

Fig. 1 A 7-year-old boy with Wolf-Hirschhorn syndrome

circumference $(\mathrm{cm})$. The growth charts cover the time period from birth until 4 years of age.

The data for each sex were divided into 30 different age groups, with 1-month intervals during the first 2 years of life, 3-month intervals during the $3 \mathrm{rd}$ and 4 th years of life. Each child contributed only one single set of data for each age group. If data from more than one examination within an interval were available, the data from the first examination were used. The growth data were compared to standard growth charts for healthy children based upon the fourth Dutch growth study of 1997 [6]. As there are no growth charts for children with WHS elsewhere in the world, no comparison could be made with growth charts from children with WHS from other countries.

Data for weight and height were transformed into logarithms before statiscal analysis in order to obtain normal distributions. All growth charts are based on means and standard deviations. The software used was SPSS version 10 and Sigmaplot version 8.02 bij SPSS Inc.

\section{Results}

Figures 2 and 3 present growth charts for height for boys and girls. Mean birth length was $43.0 \mathrm{~cm}$ in girls and $41.5 \mathrm{~cm}$ in boys, corresponding to $-3 \mathrm{SDS}$ on growth charts for healthy Dutch children. Mean height at 4 years was $87.2 \mathrm{~cm}$ for girls and $85.8 \mathrm{~cm}$ for boys, corresponding to -4 and $-4.5 \mathrm{SDS}$, respectively.

Figures 4 and 5 represent growth charts for weight for boys and girls. Mean birth weight was $1.9 \mathrm{~kg}$ for girls and

\section{Birth to $\mathbf{4 8}$ months : Girls Height-for-age}

$\begin{array}{llllllllllllllllllll}0 & 3 & 6 & 9 & 12 & 15 & 18 & 21 & 24 & 27 & 30 & 33 & 36 & 39 & 42 & 45 & 48\end{array}$

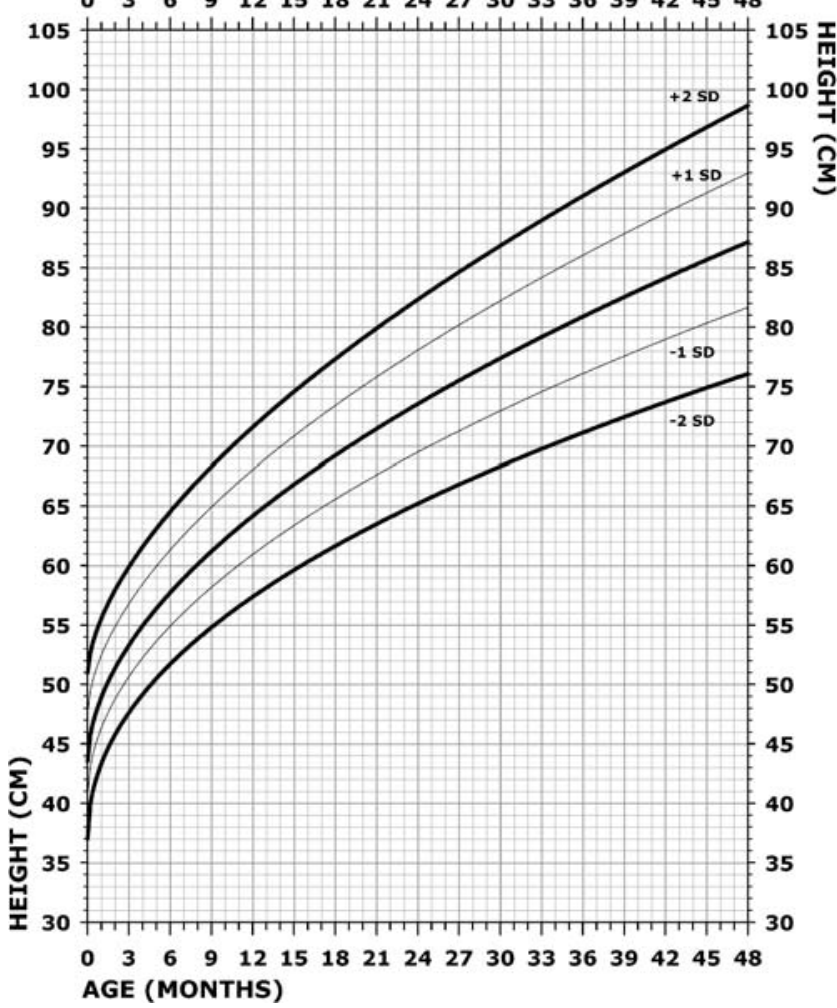

Fig. 2 Growth chart for height for girls

\section{Birth to $\mathbf{4 8}$ months : Boys Height-for-age}

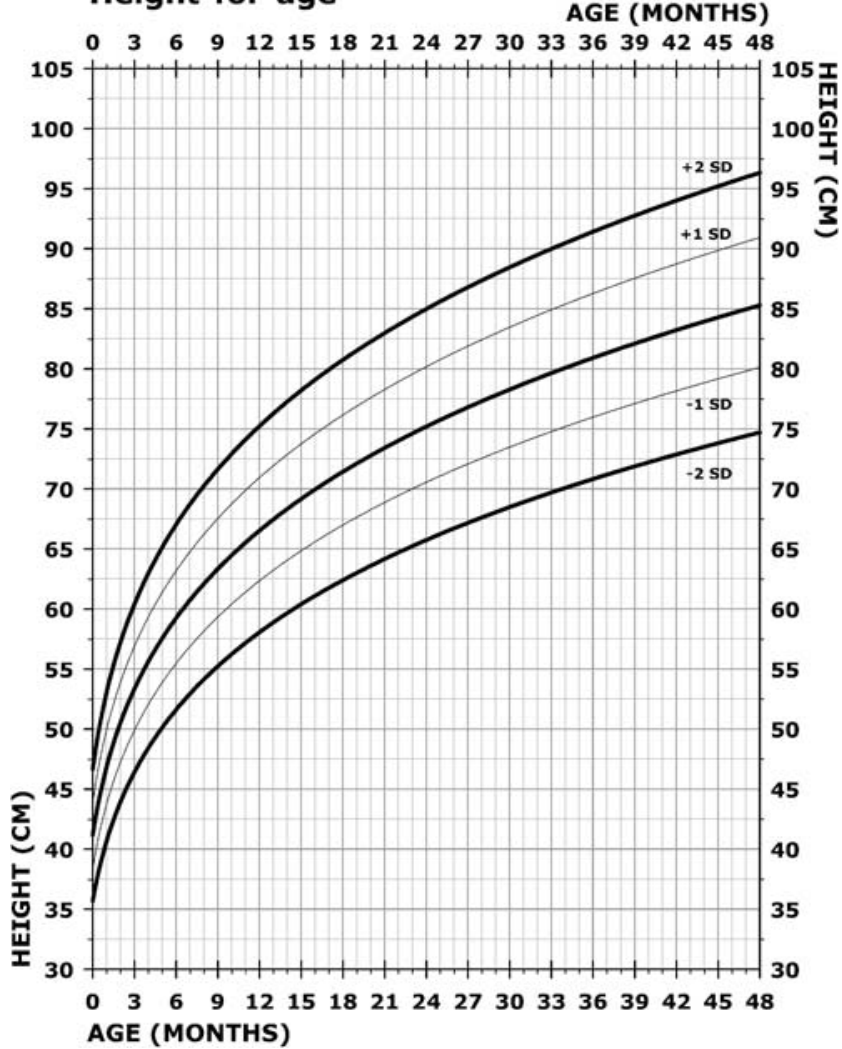

Fig. 3 Growth chart for height for boys 
Birth to 48 months : Girls Weight-for-age

AGE (MONTHS)

$\begin{array}{lllllllllllllllll}0 & 3 & 6 & 9 & 12 & 15 & 18 & 21 & 24 & 27 & 30 & 33 & 36 & 39 & 42 & 45 & 48\end{array}$
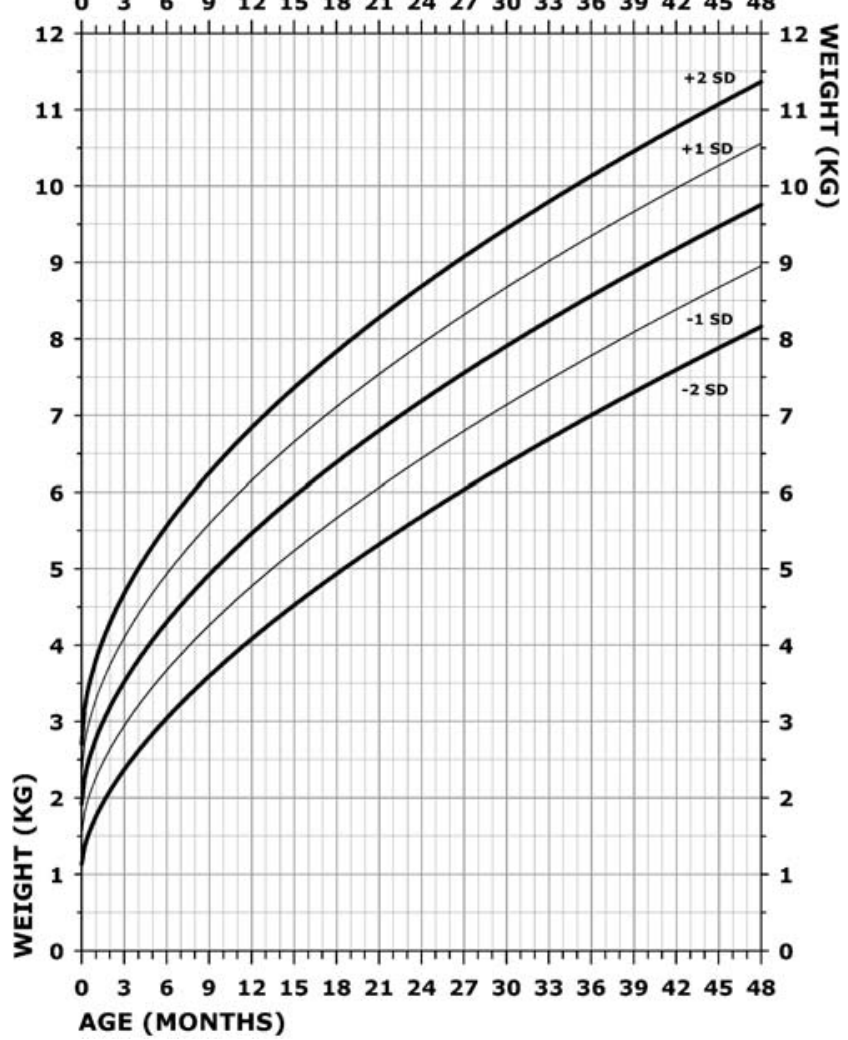

Fig. 4 Growth chart for weight for girls

$2.1 \mathrm{~kg}$ for boys, corresponding to $-3 \mathrm{SDS}$ on growth charts for healthy Dutch children. Mean weight at 4 years was $9.8 \mathrm{~kg}$ for girls and $9.7 \mathrm{~kg}$ for boys, corresponding to -4 SDS and -4.5 SDS respectively. Figure 6 represents the growth chart for head circumference for boys and girls. Mean head circumference at birth was $30.5 \mathrm{~cm}$ for girls and boys, corresponding to -3.5 SDS for both sexes on normal growth charts. Mean head circumference at 4 years was $45.8 \mathrm{~cm}$ for girls and boys, corresponding to $-3.5 \mathrm{SDS}$, respectively.

\section{Discussion}

Growth is used in pediatrics as a marker of health and is an important tool in the medical care for children. Severe growth retardation is one of the cardinal features of WHS [1]. It might be caused by genetic factors, poor feeding status, inherited parental factors and associated diseases. Whether patients with WHS suffer from an additional endocrine disorder is not known and is beyond the scope of this study. Up to date there are no WHS-specific growth
Birth to $\mathbf{4 8}$ months : Boys

Weight-for-age

AGE (MONTHS)

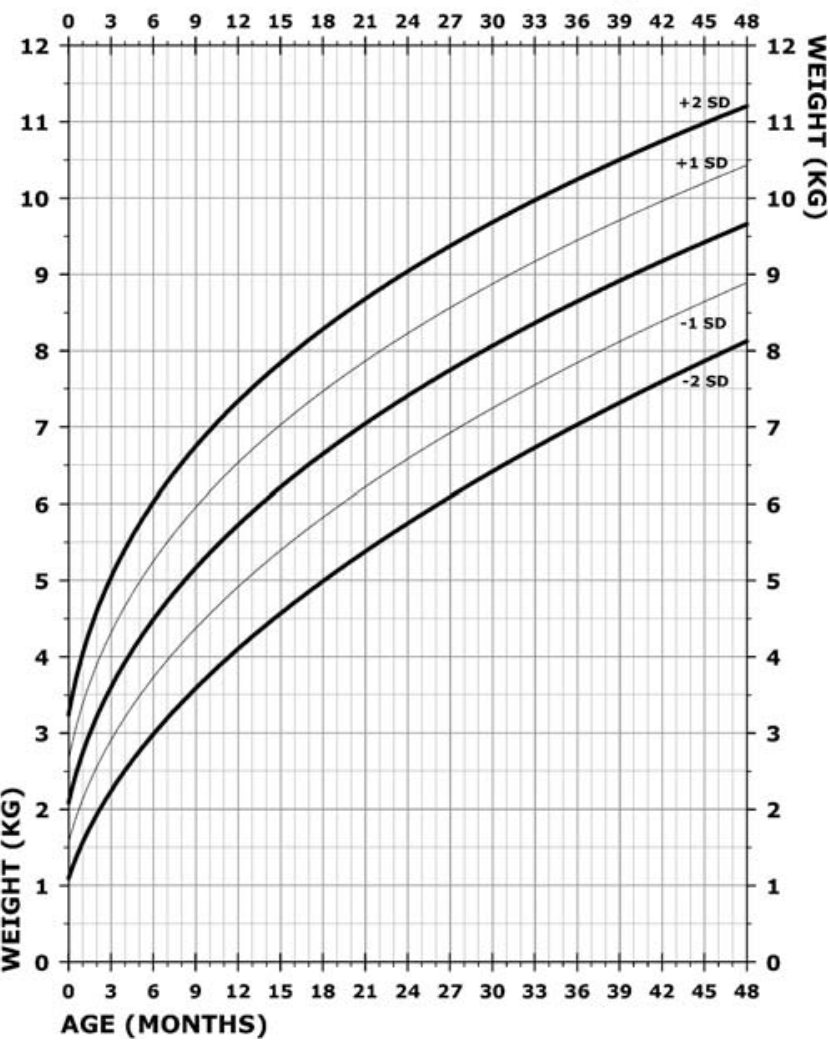

Fig. 5 Growth chart for weight for boys

charts available in contrast to more common chromosomal disorders like Down's syndrome, Turner syndrome and Prader-Willi syndrome. Although the ideal manner in constructing growth charts would be a prospective, longitudinal study based on a large study group, this method cannot be implied for rare syndromes such as WHS. To increase the number of observations we combined the available longitudinal data with crosssectional measurements. We have used data from all children with WHS, including those receiving tubefeeding. Several other associated diseases such as heart or renal disease theoretically could influence growth of the patients. Although $33 \%$ of children with WHS have congenital heart defects, these defects are in most cases not complex in nature [1]. Closure defects, hypotonia, gastro-eosphageal reflux, epilepsia, repeated infections and surgical procedures all can have a significant influence on growth. Not all patients with WHS have the same deletion size. Until now there has been no evidence of an influence of the deletion size on growth, but all studies have only involved small numbers of children. Deletion size can be expected to be of influence on growth, and therefore we tried not to include patients with 


\section{Birth to $\mathbf{4 8}$ months : Boys and Girls Height circumference-for-age}

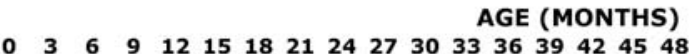

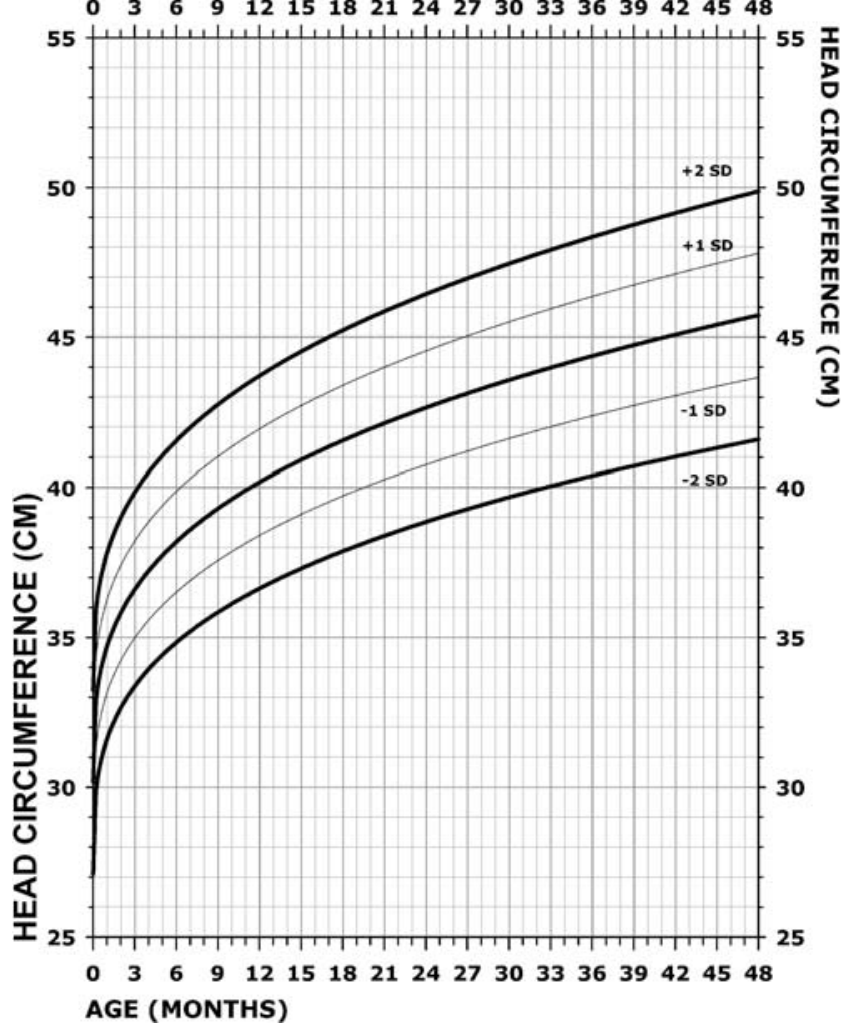

Fig. 6 Growth chart for head circumference for boys and girls

a known microdeletion. However, this study inevitably includes patients with different deletion sizes, but the number of included children was too small to show an effect on growth. Based on the available data from the
Dutch cohort, we could not identify a major co-morbidity risk factor aggravating growth retardation. Almost all children with WHS showed a marked intra-uterine growth retardation. Despite adequate feeding none of the children with WHS, demonstrated catch-up growth; all remained short with a profound microcephaly. The developed specific growth charts should be used for children with WHS from birth to 4 years of age for the estimation of their growth and health condition as standard growth charts are inapplicable in these patients. At present the authors are constructing growth charts for older children with WHS.

\section{References}

1. Battaglia A, Carye JC, Cederholm P, Viskochill DH, Brothman AR, Galasso C (1999) Natural history of Wolf-Hirschhorn syndrome: experience with 15 cases. Pediatrics 103:830-836

2. Battaglia A, Carey JC, Wright TJ (2001) Wolf-Hirschhorn (4p-) syndrome. Adv Pediatr 48:75-113

3. Cooper H, Hirschhorn K (1961) Apparent deletion of short arms of one chromosome (4 or 5 ) in a child with defects of midline fusion. Mamm Chrom Nwsl 4:14

4. Hirschhorn K, Cooper H, Firschein IL (1965) Deletion of short arms of chromosome 4-5 in a child with defects of midline fusion. Humangenetik 1:479-482

5. Lurie IW, Lazjuk GL, Ussova I, Presman EB, Gurevich DB (1980) The Wolf-Hirschhorn syndrome. Clin Genet 17:375-384

6. TNO/LUMC (1997) Fourth dutch growth study. Bohn Stafleu van Loghum 90.000.3862.6

7. Wolf U, Reinwein H, Porsh R, Schroter R, Baitsch (1965) Defizienz am den kurze Armen eines chromosomes nr. 4. Humangenetik $1: 397-413$ 